\title{
INSULATING EFFECT OF A SNOW COVER ON THE GROWTH OF YOUNG SEA ICE*
}

\author{
B. E. Holtsmark $\dagger$
}

\begin{abstract}
$\mathbf{I}^{\mathrm{x}}$ N THE spring of 1949 members of the U.S. Navy Electronics Laboratory stationed at the Arctic Research Laboratory of the Office of Naval Kesearch, Point Barrow, Alaska, studied the effect of the thermal insulation of snow cover on the growth of that season's sea ice. ${ }^{1}$ Twenty-one measurements of snow thickness made on fast sea ice are shown in Fig. 1. Under a snow cover of $10 \mathrm{~cm}$. the ice was repeatedly measured to be about $180 \mathrm{~cm}$. thick, whereas under $60 \mathrm{~cm}$. of snow it was only $135 \mathrm{~cm}$. thick. The relationship indicated here is not, however, an exact one. In nature the rate at which ice grows decreases as the thickness increases; therefore, it is reasonable to suppose that a hyperbolic type of relationship may exist between the thickness of snow and sea ice.

The scattered distribution of points measured for the ratio of snow thickness to ice was necessary because the snow cover at certain spots was too restricted to yield reliable values. For example, a snow mound one metre wide cannot effectively insulate ice $150 \mathrm{~cm}$. thick.

During the late winter and early spring of 1950 the vertical temperature was measured daily with carefully calibrated thermistors at nine levels through a section of the air-snow-ice system on the young sea ice off Point Barrow. In addition, four control areas, with varying thicknesses of snow cover, were used to measure simultaneously the different amounts of ice growth.
\end{abstract}

\section{Equipment}

Measuring equipment consisted of a number of accurately calibrated thermistors (temperature-sensitive resistance elements) and a portable, heated Wheatstone bridge to determine thermistor resistance in the field, where air temperatures down to $-50^{\circ} \mathrm{C}$ might be expected.

Nine thermistors were installed in a vertical section through the air-snowice system from 2 metres above the snow to a depth of $85 \mathrm{~cm}$. into the ice. ${ }^{2}$ The vertical spacing (Fig. 2) was arranged to obtain gradients through those layers of the system which, at that time, were believed to govern the heat flow.

The two thermistors above the snow were secured to a wooden mast one inch in diameter, securely guyed from the top and midsection with stout cotton

*Paper read at the Third Alaskan Science Conference, 22-7 September 1952.

†U.S. Navy Electronics Laboratory, San Diego, California.

1U.S.N.E.L. Oceanographic Studies Section. 1950. 'Oceanographic field observations in the Arctic near Point Barrow, Alaska'. Report No. 189, $12 \mathrm{pp}$.

2Nine thermistors were originally installed, but Nos. 16, 4 , and 8 had to be replaced during the early part of the observations by three additional thermistors, Nos. 17, 11, and 12 (Fig. 2). 

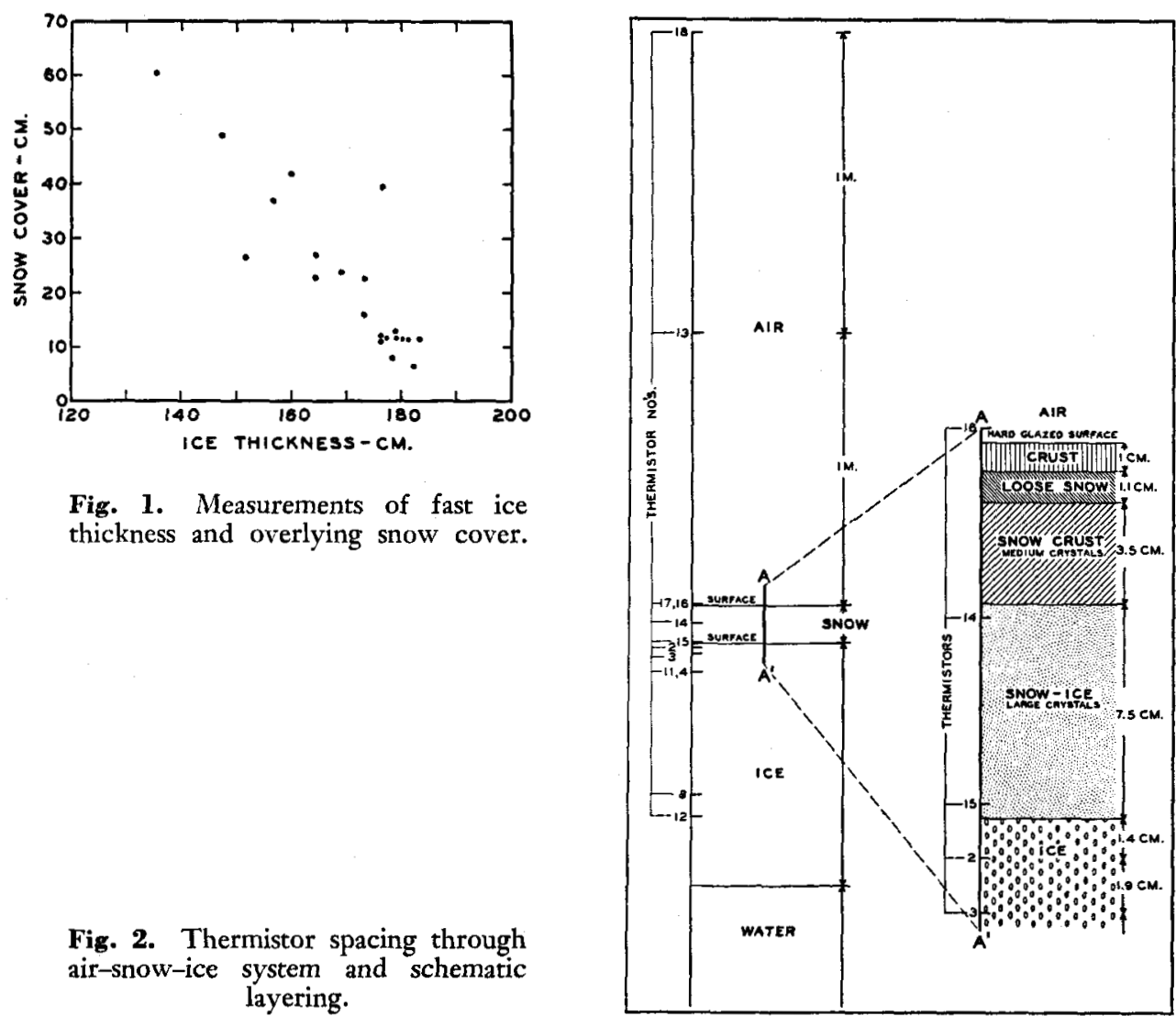

Fig. 1. Measurements of fast ice thickness and overlying snow cover.

Fig. 2. Thermistor spacing through air-snow-ice system and schematic layering.

lines anchored in the ice with spikes (Fig. 5). The thermistors were fitted with adjustable metal shields, which could be regulated to give protection from direct sunlight.

A junction box was installed near the vertical section and all thermistor leads were gathered there to protect the contacts from icing. This precaution was found to be unnecessary, however, since if the ice did form on the metal plugs it was easily removed by hand.

The Wheatstone bridge was housed in a small, specially heated, portable plywood box measuring $10 \times 6 \times 4$ inches. The bridge proper was in an inner plywood box with 1 inch of pressed cardboard insulation on all sides. All shaft connections with the interior of the box were micarta rods. The galvanometer dial face was covered with two glass plates separated by $\frac{1}{2}$ inch of air insulation. The major source of heat loss was thereby restricted to the thermistor jack leads and connections for the electrically heated copper water tank. The water for this tank, which was also inside the box, was heated at the laboratory when the equipment was not in use and the heat capacity was sufficient to keep the bridge components warm for two hours of exposure to temperatures of the order of $-40^{\circ} \mathrm{C}$. 


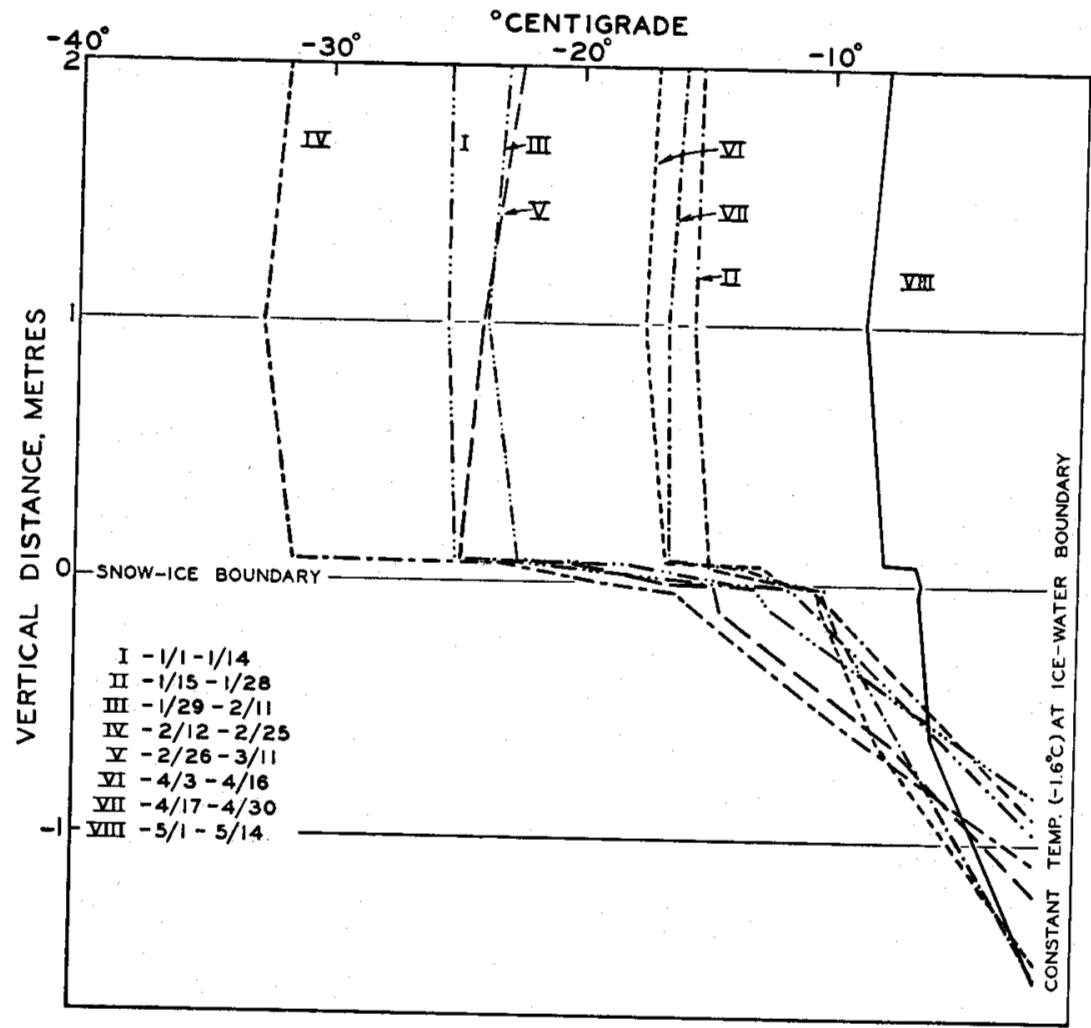

Fig. 3.

Bi-weekly average temperature profiles through air-snow-ice system, 1 January to 14 May 1950.

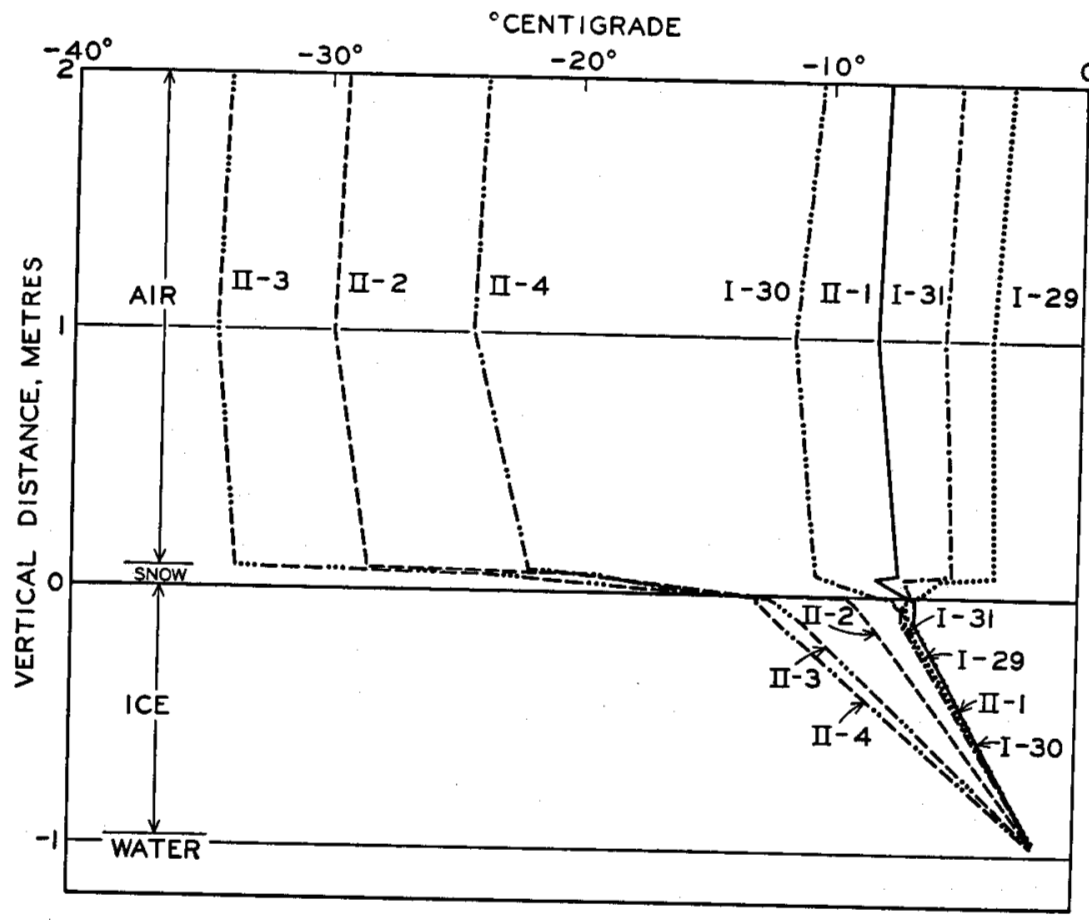

Fig. 4.

Daily temperature profiles, 29 January to 4 February 1950. 


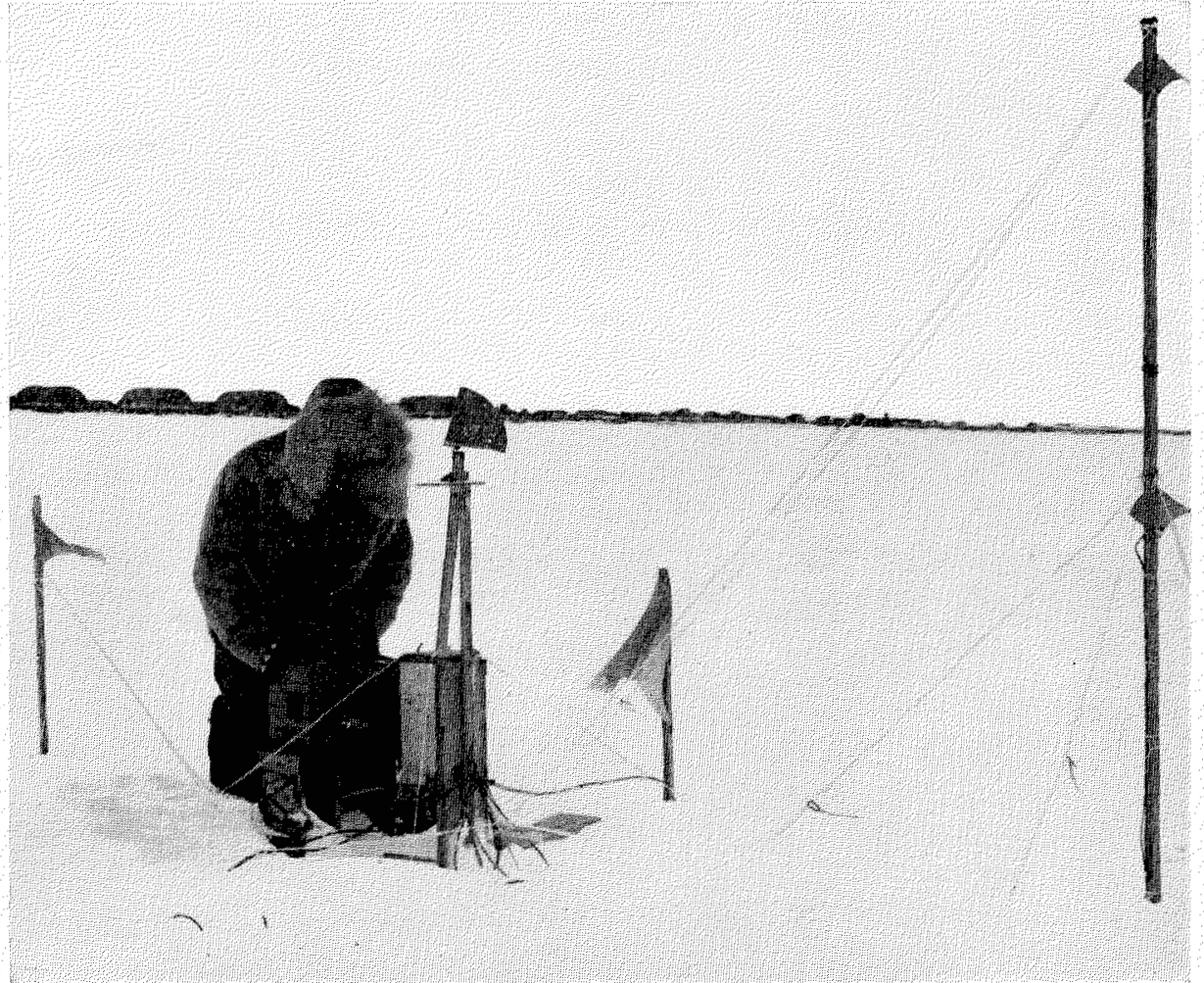

Fig. 5. Thermistor station on fast jce.

The reading of temperatures in the field was confined to selecting thermistors and rotating one potentiometer dial to balance the bridge. These operations could be performed easily with heavily mittened hands, and the thermistor resistances were recorded in air temperatures down to $-42.3^{\circ} \mathrm{C}$.

\section{Measurements}

Bi-weekly average temperature profiles are given in Fig. 3, and show that fluctuations in air temperatures decrease with distance from the air-snow surface. It can be assumed that at the extreme end of the system, at the ice-water boundary, temperature fluctuations reflect only possible variations of the freezing point of sea water. The latter, in turn, are dictated by variations in salinity: for example, a salinity of 30 per mille has a freezing point of $-1.63^{\circ} \mathrm{C}$, that of 32 per mille a freezing point of $-1.74^{\circ} \mathrm{C}$.

The lowest average air temperatures occurred during February, and the warmest at the end of the observation period in May. The effect of heat insulation through the $8-\mathrm{cm}$. thick snow blanket was impressive; for instance, while the air temperature above the snow cover fluctuated some $22^{\circ} \mathrm{C}\left(-10^{\circ} \mathrm{C}\right.$ to $-32^{\circ} \mathrm{C}$ ), the temperatures $7 \mathrm{~cm}$. below the air-snow surface fluctuated only $9^{\circ} \mathrm{C}\left(-7^{\circ} \mathrm{C}\right.$ to $\left.-16^{\circ} \mathrm{C}\right)$. The most extreme case occurred on 11 February 1950 , 
when the air temperature $0.5 \mathrm{~cm}$. above the air-snow surface was $-42.3^{\circ} \mathrm{C}$, and the air temperature at a depth of $7 \mathrm{~cm}$. in the surface snow was $-24.1^{\circ} \mathrm{C}$, a difference of $18^{\circ} \mathrm{C}$. Variations in the ice surface temperatures, while reflecting those of the atmosphere, show a time lag and are considerably less in amplitude. Thus, the extreme ice surface temperature recorded, $-20.1^{\circ} \mathrm{C}$, was on February 15, four days after the lowest temperature, $-42.3^{\circ} \mathrm{C}, 0.5 \mathrm{~cm}$. above the air-snow surface.

Typical daily vertical temperature distributions are shown in Fig. 4. On January 29 the air temperature had been close to the freezing point $\left(-2^{\circ} \mathrm{C}\right.$ to $-5^{\circ} \mathrm{C}$ ) for several days. At this time the air temperature was higher than that of the ice and hence heat was conducted from the atmosphere to the ice. A cold spell followed, and the air temperatures dropped. This fall in temperature was reflected in the ice surface temperature on the following day, January 30. Four days later, on February 3, the air temperature started to warm up. The ice surface temperature, however, fell for another day before rising. Toward the end of the season this process is reversed and heat from the air contributes to the melting of the ice.

\section{Ice thickness and snow cover}

Periodic measurements of snow cover and ice thickness were made at the thermistor station and at four control areas in the vicinity (Fig. 6). The latter measured 5 metres $\times 5$ metres, as this was the largest area that one man could reasonably maintain.

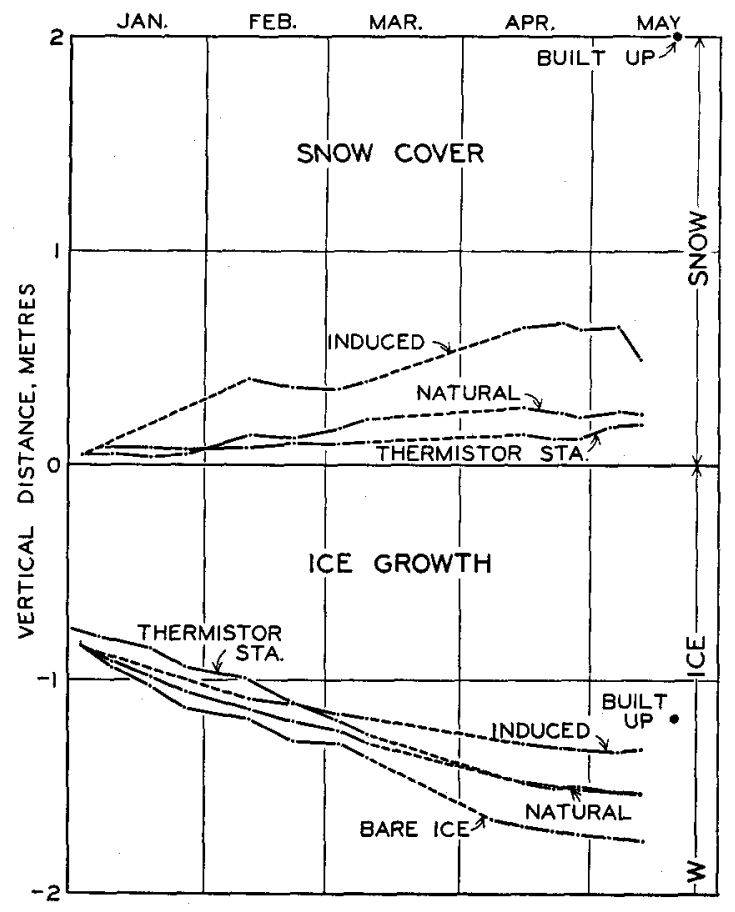

Fig. 6. Ice growth at thermistor station and four control areas. 
The first control area was kept as free of snow as possible by daily shovelling. The second area was chosen to show natural snow cover and had to be free of surface irregularities which would cause surface drifts; it proved to be satisfactory, the maximum depth of snow cover reaching only $27 \mathrm{~cm}$. Snow cover was induced upon the third control area by building a snow barrier one metre high, around which the drifting snow could accumulate to a natural maximum thickness; the induced snow reached a depth of $67 \mathrm{~cm}$. Snow was shovelled on to the fourth control area throughout the season to obtain a maximum possible thickness. Progress was slow at first because of the scant snow deposit in January. However, as the pile grew in height drifts formed on the lee side and progress increased. When the pile had reached a height of 1.5 metres, a snow-block wall was erected around the area and snow was built up to a final thickness of 2 metres at the end of March.

Measurements of snow cover and ice thickness were made about once a week except in the built-up snow-cover area. It was undesirable to drill the latter until a maximum snow cover had been achieved. Then it was impracticable to do so without seriously disturbing the insulating properties of the cover. Therefore one drilling only was made in this built-up snow-cover area at the end of the observational period. In the other areas, no drillings were made during a period of forced inactivity, indicated with dashed lines in Fig. 6. The measurements show reasonably good agreement. Whereas the ice thickness varied by some $3 \mathrm{~cm}$. between the thermistor station and the natural snow-cover area in January, at the beginning of the season, it was practically identical towards the end, in May. In the induced snow-cover area, where snow reached a depth of $67 \mathrm{~cm}$, the ice thickness was $133 \mathrm{~cm}$. The ice grew thickest in the bare-ice area, measuring $176 \mathrm{~cm}$., and was thinnest under the built-up snow-cover, measuring only $117 \mathrm{~cm}$. Even this crude method of measurement showed a 50 per cent increase in ice growth between the extreme snow depths. It is quite probable, moreover, that the ice under the built-up cover would have been even less if the 2 metre-thick cover could have been established at the beginning of the season. As it was, the ice had begun to sag under the snow load, as shown by the amount of water which poured over the ice surface as the measuring hole was drilled.

Periodic measurements of young sea ice growth in five areas, each with different thicknesses of snow cover ranging from nothing to 2 metres, show that a relationship exists between cover thickness and ice growth. The growth of the ice with no snow cover was nearly 50 per cent greater than that under 2 metres of snow. Because of the complex structure of the snow cover, however, a much more detailed study is necessary to explain fully the heat insulating phenomenon. Present knowledge is not sufficient to predict ice thickness from snow-cover thickness. 